\title{
proBDNF inhibits the proliferation and migration of OLN-93 oligodendrocytes
}

\author{
SHEN LIU ${ }^{1,2}$, WEI GUO ${ }^{2}$, HENGXING ZHOU ${ }^{2}$, LIANG TANG ${ }^{3}$, \\ SHIQING FENG ${ }^{2}$, JIN-HUA ZHONG ${ }^{1}$ and XIN-FU ZHOU ${ }^{1}$
}

\begin{abstract}
${ }^{1}$ School of Pharmacy and Medical Science and Sansom Institute, Division of Health Sciences, University of South Australia Adelaide SA5000, Australia; ${ }^{2}$ Orthopaedic Department of Tianjin Medical University General Hospital, Tianjin 300052;

${ }^{3}$ Orthopaedic Department of Tianjin Haihe Hospital, Tianjin 300000, P.R. China
\end{abstract}

Received April 20, 2017; Accepted May 3, 2018

DOI: $10.3892 / \mathrm{mmr} .2018 .9407$

\begin{abstract}
In contrast with mature brain-derived neurotrophic factor (mBDNF), proBDNF induces cell apoptosis. However, the function of proBDNF in oligodendrocytes remains unclear. In the present study, the OLN-93 oligodendroglia cell line was utilized as an in vitro model to analyse the functions of proBDNF in oligodendroglia. p75NTR, sortilin and proBDNF were expressed in cultured OLN-93 cells. It was indicated that proBDNF inhibited OLN-93 cell proliferation in a dose-dependent manner as determined using the MTT assay and BrdU staining. Furthermore, proBDNF suppressed the migration of OLN-93 cells as demonstrated using the scratch assay. proBDNF also decreased cell viability and promoted apoptosis as indicated by activated cysteine-aspartic acid protease-3 (caspase-3) immunocy tochemistry. Notably, anti-proBDNF treatment neutralized the effect of proBDNF and resulted in increased cell proliferation and migration and decreased apoptosis. However, these effects were not observed in the presence of recombinant p75NTR extracellular domain-human FC fusion protein and p75NTR antibody, indicating that proBDNF imparts its inhibitory effects on oligodendrocytes through the p75NTR signal pathway.
\end{abstract}

Correspondence to: Dr Xin-Fu Zhou, School of Pharmacy and Medical Science and Sansom Institute, Division of Health Sciences, University of South Australia, 73 North Terrace, Adelaide SA5000, Australia

E-mail: xin-fu.zhou@unisa.edu.au

Dr Shiqing Feng, Orthopaedic Department of Tianjin Medical University General Hospital, 154 Anshan Road, Heping, Tianjin 300052, P.R. China

E-mail: fengsq@hotmail.com

Abbreviations: BDNF, brain-derived neurotrophic factor; p75NTRECD-fc, p75NTR extracellular domain-human FC fusion protein; SCI, spinal cord injury; CNS, central nervous system; OPC, oligodendrocyte precursor cell

Key words: proBDNF, oligodendrocyte, p75NTR, sortilin

\section{Introduction}

Mature brain-derived neurotrophic factor (mBDNF), as well as its precursor proBDNF are widely distributed in the central nervous system (CNS) as a member of the neurotrophin family (NTs). The current view is generally believed that NTs has a protective effect on neurons (1). Interestingly, mature NTs (for example, mBDNF) are not the primary gene products. They are removed from a relatively large neurotrophic factor precursor (for example, proBDNF). The full length protein of proBDNF is about $35 \mathrm{kDa}$. After shearing, a mature molecule (mBDNF) with a length of about $13.5 \mathrm{kDa}$ and a precursor fragment (pre-domain) of about $20 \mathrm{kDa}$ are obtained. Usually, proBDNF has two processes to be cut by enzyme: One is cleaved endogenously and then secreted to the extracellular matrix (2), the other is directly secreted to the extracellular domain, and then modified in the extracellular environment (3).

Deffer from the mBDNF, which promotes neuron survival and regeneration, which are important to functional recovery after injury to the nerve system (4), no one mentioned whether the exogenous proBDNF may have certain functions. People thought proBDNF was just a middle product. In 2001, Lee et al reported the inhibitory effect of proBDNF on neurons (5). Beattie found that full-length proNGF secreted into the extracellular binding to p75 neurotrophin receptor (p75NTR) mediated apoptosis in neurons and glial cells (6). In particular, our previous study found that the inhibitory effect of proBDNF on cells was induced only after nerve injury. After spinal cord injury, proBDNF could inhibit the regeneration of axons (7).

In our previous study, we have shown that endogenous proBDNF can inhibit macrophage infiltration and disturb demyelination and remyelination after SCI (7). This indicates that proBDNF may affect cells other than neurons during post-injury repair.

The present study focused on the functions of proBDNF in proliferation and migration of oligodendroglia. We observed that proBDNF can inhibit proliferation and migration of OLN-93 cells, a permanent oligodendroglia cell line. Moreover, anti-proBDNF treatment could be effective in protecting cells from apoptosis and in promoting cell proliferation and 
migration. Therefore, blocking proBDNF may be a therapeutic target for traumatic injuries in CNS.

\section{Materials and methods}

Cell culture and maintenance. The OLN-93 oligodendroglia cell line was utilized in this study. OLN-93 cells are known to express several oligodendroglial markers; however, they do not exhibit characteristics of astrocytes (8). Cells were incubated at $37^{\circ} \mathrm{C}$ and $5 \% \mathrm{CO}_{2}$ in Dulbecco's modified Eagle's medium (DMEM)/F12 with 10\% fetal bovine serum (FBS; both Gibco; Thermo Fisher Scientific, Inc., Waltham, MA, USA). Growth medium was changed twice a week. When the cells reached $70 \%$ confluency, they were digested with $1 \%$ trypsin/EDTA (Invitrogen; Thermo Fisher Scientific, Inc.) at $37^{\circ} \mathrm{C}$ for $2 \mathrm{~min}$. FBS was added to stop the digestion once the cells were round and floating. Cells were then seeded in plates or flasks and maintained in an incubator.

One subset of cells was directly fixed for fluorescent immunohistochemical staining using primary antibodies against proBDNF, p75NTR and sortilin, whereas another subset of cells was treated with serial concentrations of recombinant proBDNF $(1,3,10,30,100 \mathrm{ng} / \mathrm{ml})$; bovine serum albumin (BSA; $100 \mathrm{ng} / \mathrm{ml}$ ) treatment was used as a control. Meanwhile, sheep anti-proBDNF antibody $(5,10 \mu \mathrm{g} / \mathrm{ml})$, monoclonal proBDNF antibody (PB192E; $100 \mathrm{ng} / \mathrm{ml}$ ), mouse anti-p75NTR antibody (10 $\mu \mathrm{g} / \mathrm{ml} ; 9,650$ from Moses Chao), recombinant p75NTR extracellular domain-human FC fusion protein (p75NTRECD-fc; $3 \mu \mathrm{g} / \mathrm{ml}$ ), and normal $\operatorname{IgG}(10 \mu \mathrm{g} / \mathrm{ml})$ were also administrated in in vitro observations.

p75NTRECD-fc and the recombinant proBDNF with harbouring an RR-AA mutation on the cleavage site were produced as previously described and characterized by Fan et al (9). Sheep anti-proBDNF antibody is able to specifically recognise proBDNF; however, it cannot recognise mature BDNF and other NTs $(7,8)$. Cell viability, proliferation, migration and apoptosis were determined using the MTT assay, BrdU staining, scratch assay and activated caspase-3 staining respectively.

Immunocytochemistry. First, cells were seeded at $10^{5}$ cells/well on a pre-treated glass coverslip in a 24-well plate. When they reached $70 \%$ confluency, $4 \%$ paraformaldehyde (PFA) was added to fix the cells at room temperature for $10 \mathrm{~min}$. The fixed cells were subsequently subjected to a PBS wash three times before being immersed in blocking buffer (2\% BSA, $0.5 \%$ Triton X-100, $0.1 \%$ Tween-20,5\% donkey serum) at room temperature for $60 \mathrm{~min}$. Rabbit anti-p75 (1:1,000; Abcam, Cambridge, UK), sheep anti-proBDNF ( $5 \mu \mathrm{g} / \mathrm{ml}$; University of South Australia, Adelaide, Australia) and rabbit anti-sortilin (1:1,000; Sigma-Aldrich; Merck KGaA, Darmstadt, Germany) antibodies were then introduced as primary antibodies and incubated with the cells at $4^{\circ} \mathrm{C}$ for overnight. Then, after washing the cells three times PBST, sheep anti-rabbit IgG CY3 (1:1,000; Invitrogen; Thermo Fisher Scientific, Inc.) and donkey anti-sheep IgG CY3 (1:1,000; EMD Millipore, Billerica, MA, USA) were applied as secondary antibodies. In addition, DAPI (1:1,000; Sigma-Aldrich; Merck KGaA) was diluted in the antibody solution to serve as a nuclear dye. Subsequently, cells were incubated with corresponding secondary antibody and
DAPI at room temperature for $60 \mathrm{~min}$. Finally, after washing the cells three times, fluorescent images of the cells were captured using an Olympus BX-50 (Olympus Corp., Tokyo, Japan) fluorescent microscope equipped with a CCD camera.

Western blot analysis. Cells were seeded at $10^{6}$ cells/well in a 6-well plate, incubated at $37^{\circ} \mathrm{C}$ and $5 \% \mathrm{CO}_{2}$ and subsequently lysed using RIPA buffer [20 mM Tris-HCl ( $\mathrm{pH} 7.5)$, $150 \mathrm{mM} \mathrm{NaCl}, 1 \mathrm{mM} \mathrm{Na}{ }_{2}$ EDTA, $1 \mathrm{mM}$ EGTA, $1 \%$ NP-40, $1 \%$ sodium deoxycholate, $2.5 \mathrm{mM}$ sodium pyrophosphate, $1 \mathrm{mM} \beta$-glycerophosphate, $1 \mathrm{mM} \mathrm{Na} \mathrm{VO}_{4}, 1 \mathrm{mM}$ phenylmethylsulphonyl fluoride, $1 \mu \mathrm{g} / \mathrm{ml}$ leupeptin] when they reached a confluency of $70 \%$. After sonication and centrifugation to remove cell debris, the lysate was loaded onto a sodium dodecyl sulphate polyacrylamide gel, containing stacking $(0.5 \%)$ and a separating gel (10\%). On completion of electrophoresis, proteins were transferred onto a nitrocellulose membrane (GE Healthcare, Chicago, IL, USA) using the semi-dry method (Bio-Rad, Berkeley, CA, USA) at $20 \mathrm{~V}, 20 \mathrm{~min}$. The membrane was then washed with PBS three times and blocked with a blocking buffer (5\% skim milk in PBS) for $1 \mathrm{~h}$ at room temperature. Rabbit anti-p75 (1:1,000; Abcam), sheep anti-proBDNF ( $5 \mu \mathrm{g} / \mathrm{ml}$; University of South Australia) and rabbit anti-sortilin (1:1,000; Sigma-Aldrich; Merck KGaA) antibodies were subsequently added as primary antibodies, followed by incubation at $4^{\circ} \mathrm{C}$ for overnight. Before and after triple washes with PBST, goat anti-rabbit IgG-HRP $(1: 3,000)$ and goat-anti-sheep IgG-HRP $(1: 3,000$; both Sigma-Aldrich; Merck KGaA) were co-incubated with the membrane for $1 \mathrm{~h}$ at room temperature. ECL substrate solutions A \& B (GE Healthcare) were mixed and added onto the membrane in order to observe any potential fluorescent protein bands. Finally, the film was developed in a dark room to obtain results.

Cell viability assay. Cells were seeded at $10^{4}$ cells/well in a 96-well plate, followed by incubation at $37^{\circ} \mathrm{C}$ and $5 \% \mathrm{CO}_{2}$ for overnight to allow the cells to attach to the bottom of the wells. After washing the cells with PBS three times, the cells were cultured in a serial concentration of $\operatorname{proBDNF}(1,3,10$, $30,100 \mathrm{ng} / \mathrm{ml}$ ) or in a serial concentration of proBDNF and monoclonal proBDNF antibody PB192E $(100 \mathrm{ng} / \mathrm{ml})$ in an FBS-free medium. BSA (100 ng/ml) treatment was used as a control. After $20 \mathrm{~h}, 10 \mu \mathrm{l}$ of MTT solution $(5 \mathrm{mg} / \mathrm{ml}$ in PBS; Sigma-Aldrich-Aldrich; Merck KGaA) was added to each well, followed by incubation for an additional $4 \mathrm{~h}$. Subsequently, $100 \mu 1$ of filter-sterilized solubilisation solution (10\% SDS in $0.01 \mathrm{M} \mathrm{HCl}$ ) was added to each well and incubated overnight at $37^{\circ} \mathrm{C}$ to dissolve the insoluble purple formazan product in order to produce a coloured solution. Finally, the optical density (OD) of the solution in each well was measured at $595 \mathrm{~nm}$ using a multi-well scanning spectrophotometer (Bio-Rad Model 2550 EIA Reader); a wavelength of $620 \mathrm{~nm}$ was used as a reference.

BrdU proliferation assay. Cells were at first seeded at $5 \times 10^{5}$ cells per well on a pre-treated glass coverslip in a 24-well plate. Approximately $200 \mu \mathrm{l}$ of $\mathrm{BrdU}(80 \mu \mathrm{M}$ BrdU-medium solution; Sigma-Aldrich; Merck KGaA) was then added to each well, followed by incubation at $37^{\circ} \mathrm{C}$ and 
A

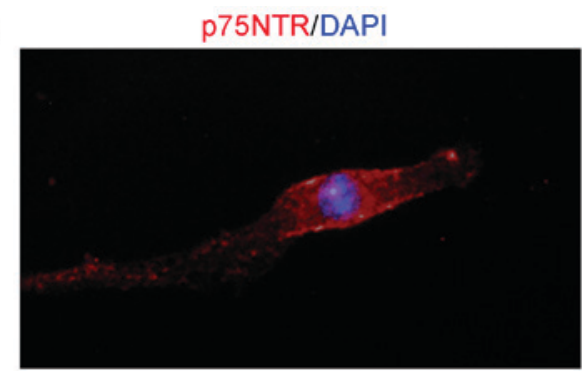

C

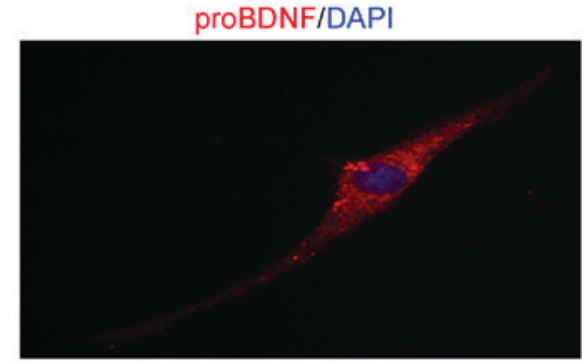

E

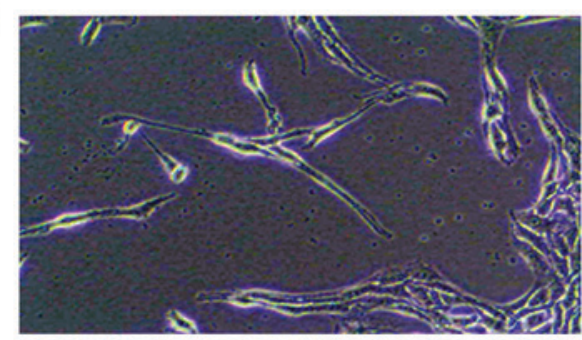

B

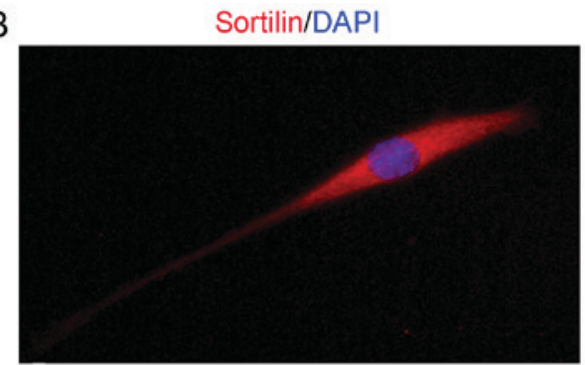

D

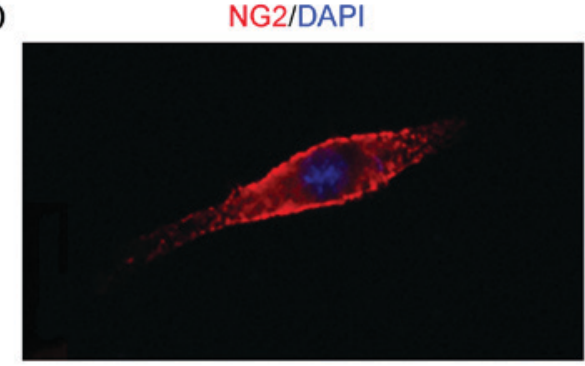

F

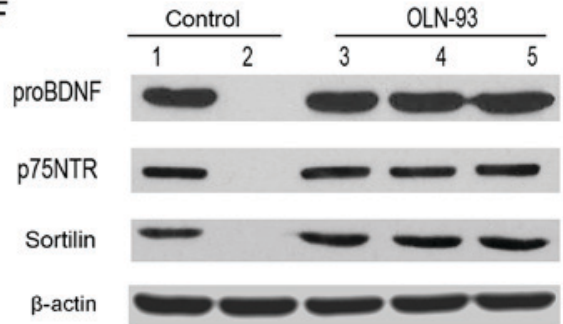

Figure 1. OLN-93 cells express p75NTR, sortilin, proBDNF and NG2. Immunohistochemistry analysis indicated that cultured OLN-93 cells were positively stained with (A) p75NTR, (B) sortilin (C), proBDNF and (D) NG2, which is a typical marker of OPCs (magnification, x60). (E) Cellular morphology of OLN-93 cells after 7 days culture (magnification, x20). (F) Western blot was analysis employed to examine the expression of p75NTR, sortilin and proBDNF. p75NTR, p75 neurotrophin receptor; BDNF, brain-derived neurotrophic factor; OPC, oligodendrocyte precursor cell.

$5 \% \mathrm{CO}_{2}$ for $24 \mathrm{~h}$. The cells were then fixed in $4 \%$ PFA and washed with PBS three times. After a $1 \mathrm{~h}$ incubation in $\mathrm{HCl}$ and neutralization in boric buffer ( $\mathrm{pH} 8.0-8.5)$, the cells were blocked using a blocking buffer (2\% BSA, $0.5 \%$ Triton X-100, $0.1 \%$ Tween-20, 5\% donkey serum). An anti-BrdU antibody (1:1,000; DSHB; University of Iowa, Iowa City, USA) was incubated with the cells as a primary antibody. Then, after washing the cells with PBST three times, cells were subjected to secondary antibody of goat anti-mouse IgG CY3 (1:1,000; Invitrogen; Thermo Fisher Scientific, Inc.) and DAPI (1:1,000; Sigma-Aldrich; Merck KGaA). After washing the cells three times, the number of BrdU/DAPI-positive cells was counted at five random fields per slice at magnification, x10 under a fluorescence microscope.

Scratch assay. The scratch assay was performed as previously described (10). Briefly, OLN-93 cells cultured in a 6-well plate were wounded using a sterile P20 pipette tip, followed by washing with culture medium to remove cell debris. The cells were then treated with 1, 3, 10, 30, and $100 \mathrm{ng} / \mathrm{ml}$ proBDNF and $100 \mathrm{ng} / \mathrm{ml} \mathrm{BSA}$ for 24 or $48 \mathrm{~h}$, respectively. Subsequently, cells were fixed by $4 \%$ PFA for $10 \mathrm{~min}$ then stained by $0.05 \%$ crystal violet for $30 \mathrm{~min}$. After washed by PBS, phase contrast images were captured in 6 different fields of every wound using an inverted microscope (Olympus IX-71; Olympus Corp.). Cells that migrated into the wound space were counted in the captured image. The experiments were performed in triplicates.
Cell apoptosis assay. OLN-93 cells at $5 \times 10^{4}$ cells per well were seeded in 24-well plates. When the cells reached $90 \%$ confluency, they were washed three times with PBS and treated with proBDNF, proBDNF antibody and BSA consecutively at $37^{\circ} \mathrm{C}$ and $5 \% \mathrm{CO}_{2}$ for $24 \mathrm{~h}$. After treatment, cells were fixed in $4 \%$ PFA at room temperature for $10 \mathrm{~min}$ and then washed with PBS before being blocked using a blocking buffer (2\% BSA, $0.5 \%$ Triton X-100, 0.1\% Tween-20, 5\% donkey serum). Next, rabbit anti-activated caspase-3 (1:1,000; EMD Millipore) was co-incubated with the cells at $4^{\circ} \mathrm{C}$ for overnight. Then, sheep anti-rabbit IgG FITC (1:1,000; Abcam) and DAPI (1:1,000; Sigma-Aldrich; Merck KGaA) were applied and co-incubated with the cells at room temperature for $1 \mathrm{~h}$. After washing the cells 3 times, fluorescent images of the cells were captured using an Olympus BX-50 fluorescent microscope.

Data acquisition and statistical analysis. Five visual fields were randomly selected from superior, inferior and central parts as well as from left-hand and right-hand sides of each slide for fluorescence microscopy analysis. Images at magnifications of x10, x20 and x60 were obtained using an Olympus BX-50 fluorescent microscope.

The total number of cells and positively-stained cells were counted using Image J. Quantitative analysis was performed for all experiments using SPSS for Windows v. 13.0. All data are presented as mean \pm standard error of the mean (SEM). Data were analysed using one-way analysis of variance (ANOVA), 

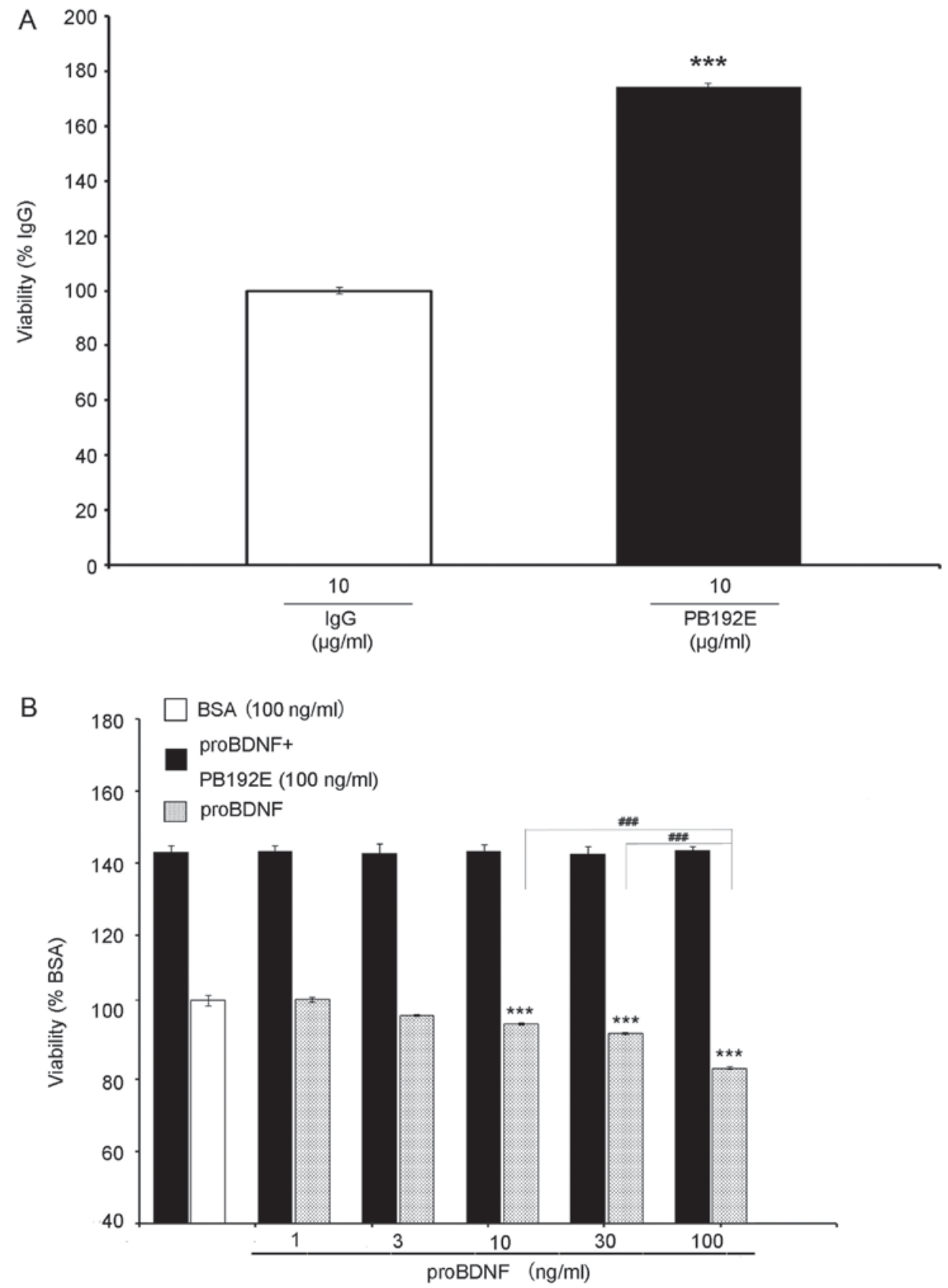

Figure 2. Cell viability assay by MTT method. (A) proBDNF monoclonal antibody PB192E promotes OLN-93 cell activities compared with normal IgG. (B) proBDNF inhibits cell viability in a dose-dependent manner, however proBDNF antibody PB192E neutralized the inhibitory effect. ${ }^{* * * *} \mathrm{P}<0.001$ vs. the BSA. ${ }^{\# \# /} \mathrm{P}<0.001$ vs. proBDNF treated group by different dosage $(10,30,100 \mathrm{ng} / \mathrm{ml})$. ANOVA, $\mathrm{F}=25.44$. BSA, bovine serum albumin; BDNF, brain-derived neurotrophic factor; ANOVA, one-way analysis of variance.

followed by Tukey's post-hoc tests, where appropriate, or t-test for paired groups. $\mathrm{P}<0.05$ was considered to indicate a statistically significant difference. All experiments were repeated at least 3 times.

\section{Results}

OLN-93 cells express proBDNF and its receptors. OLN-93 cells were maintained in DMED/F12 1:1 medium. In the presence of $10 \%$ FBS, cell proliferation occurred at a high rate (8). All the cells expressed proBDNF, p75NTR and sortilin as shown by fluorescent immunocytochemistry (Fig. 1A-C). The typical oligodendroglia cell marker NG2
(Fig. 1D), which was also used to label oligodendrocytes in spinal cord was also expressed (11). Cell growth was observed to be density-dependent. Cells were mainly bipolar with long cellular extensions at lower confluency; they formed large clumps interconnected with long, thin cellular processes at higher confluency (Fig. 1E). Moreover, Western blot analysis using the cell lysate showed bands of proBDNF, p75NTR and sortilin at the corresponding molecular weights (Fig. 1F). These results indicated that OLN-93 cells expressed endogenous proBDNF and its receptors p75NTR and sortilin.

proBDNF inhibits OLN-93 cell viability. To examine the effect of proBDNF on OLN-93 cells, we used a monoclonal 

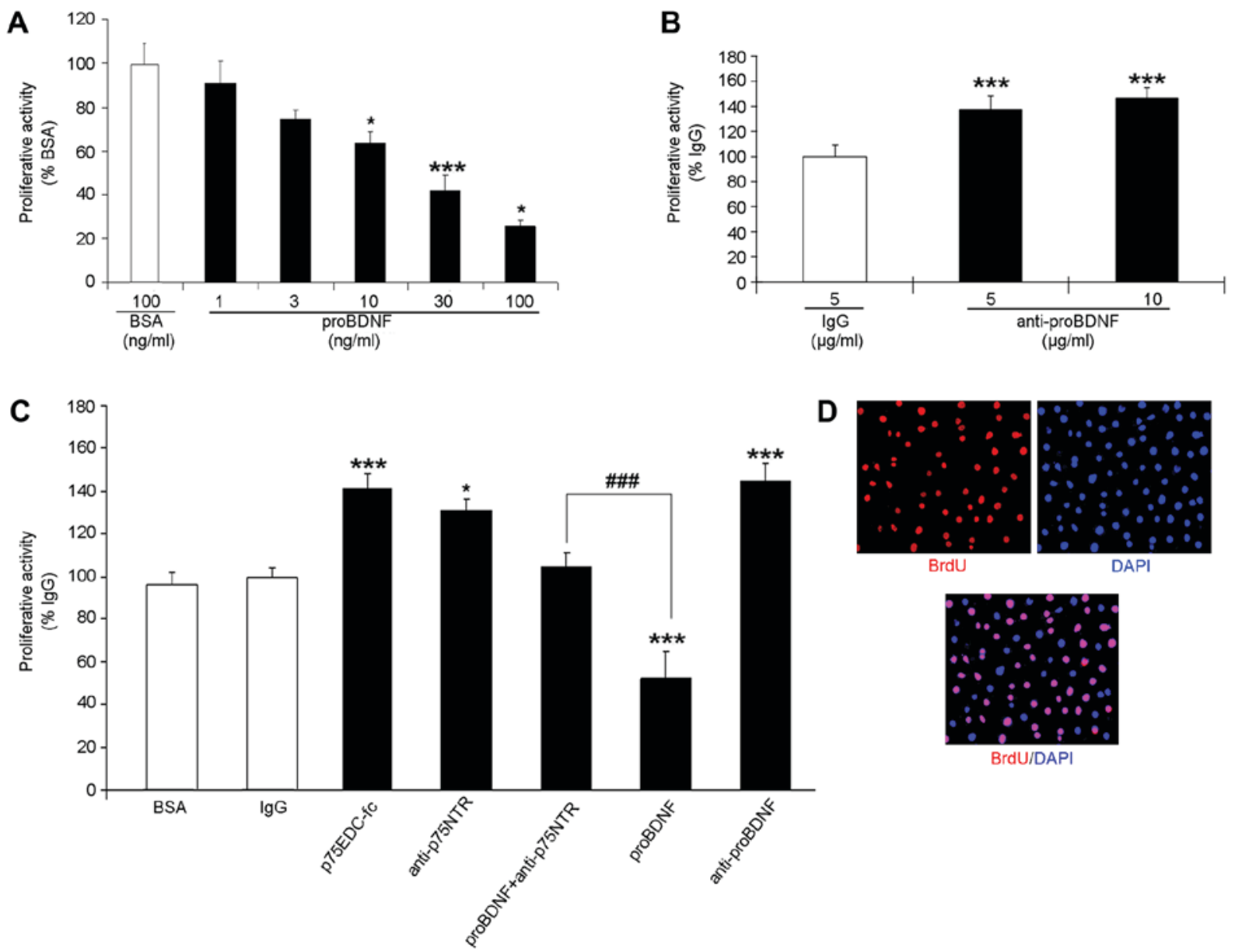

BrdU/DAPI

Figure 3. Quantitative assessment of the proliferative activities in OLN-93 cells. (A) Cells were treated with serial concentration of proBDNF at 0, 1, 3, 10, 30, $100 \mathrm{ng} / \mathrm{ml}$; ANOVA, F=21.603 (B) Cells were treated with 5 and $10 \mu \mathrm{g} / \mathrm{ml}$ proBDNF antibody. ANOVA, F=20.144 (C) Cells were treated with p75NTRecd-FC, p75NTR antibody, respectively, and proBDNF + p75NTR antibody. The activities were measured against the BSA group and calculated as the \% activity of BSA. ANOVA $\mathrm{F}=195.301$. ${ }^{*} \mathrm{P}<0.05,{ }^{* * * *} \mathrm{P}<0.001$ vs. the BSA group, ${ }^{\# \# \#} \mathrm{P}<0.001$ vs. proBDNF treated group. (D) Photomicrograph of cultured OLN-93 cells, which have been immunostained with BrdU (red) and DAPI (blue) (magnification, x40). BSA, bovine serum albumin; BDNF, brain-derived neurotrophic factor; ANOVA, one-way analysis of variance.

proBDNF antibody (PB192E), raised against the pro-domain of BDNF, to neutralise the effects of proBDNF. Cells treated with $\mathrm{PB} 192 \mathrm{E}$ at $10 \mu \mathrm{g} / \mathrm{ml}$ were more active than those treated with normal IgG (Fig. 2A), indicating that endogenous proBDNF may have inhibited the cell growth.

MTT assay revealed that proBDNF imparts a toxic effect on cell viability. Treated with serial concentrations of proBDNF $(1,3,10,30,100 \mathrm{ng} / \mathrm{ml})$, the cell growth curve demonstrated a significant growth inhibition at $10 \mathrm{ng} / \mathrm{ml}$, with the highest growth inhibition at $100 \mathrm{ng} / \mathrm{ml}$ (Fig. 2B) ( $\mathrm{P}=0.000904)$, indicating a dose-dependent response.

Then, we treated the cells with serial concentrations of proBDNF $(1,3,10,30,100 \mathrm{ng} / \mathrm{ml})$ and PB192E antibody $(100 \mathrm{ng} / \mathrm{ml})$. Cells in this group had significantly higher bioactivity than those in the BSA and proBDNF-treated groups (Fig. 2B) ( $\mathrm{P}=0.000194)$, indicating that $\mathrm{PB} 192 \mathrm{E}$ antibody can neutralise exogenous proBDNF as well.

proBDNF inhibits, but anti-proBDNF promotes, OLN-93 cell proliferation. Quantitative assessment of the proliferative activities in OLN-93 cells were performed (Fig. 3). BrdU/DAPI double-labelling was applied to the OLN-93 cell proliferation assay (Fig. 3C). The proliferating cells were $\mathrm{BrdU}^{+} / \mathrm{DAPI}^{+}$, whereas the non-proliferating ones were only $\mathrm{DAPI}^{+}$. The percentage of $\mathrm{BrdU}^{+} / \mathrm{DAPI}^{+}$cells in the proBDNF-treated groups was significantly lower than that in the BSA group, illustrating a dose-dependent inhibition (Fig. 3A) $(\mathrm{P}=0.0206$ in $10 ; \mathrm{P}=0.0420$ in $100 \mathrm{ng} / \mathrm{ml} ; \mathrm{P}=0.000126$ in $30 \mathrm{ng} / \mathrm{ml}$ ).

To confirm our results, we used polyclonal sheep anti-proBDNF antibodies to neutralise endogenous proBDNF. We found that cells treated with polyclonal antibodies showed higher proliferative activities than those treated with normal sheep IgG (Fig. 3B) ( $\mathrm{P}=0.000105)$. These experiments indicate that OLN-93 cells secrete endogenous proBDNF, which inhibits their growth.

Inhibitory effect of proBDNF on OLN-93 cell proliferation is blocked by soluble p 75 receptor body or $p 75$ antibodies. To investigate the possible pathway by which proBDNF exerts an inhibitory on OLN-93 cells, recombinant fusion molecule of p75NTRECD-fc and p75NTR functional antibody were utilized. These have been used in our previous study as competitive inhibitors to block p75NTR signal transduction extracellularly (12). In this study, we treated OLN-93 cells with $3 \mu \mathrm{g} / \mathrm{ml}$ of p75NTRECD-fc protein and $10 \mu \mathrm{g} / \mathrm{ml}$ of anti-p75NTR for $24 \mathrm{~h}$. Then, BrdU/DAPI double-labelling 

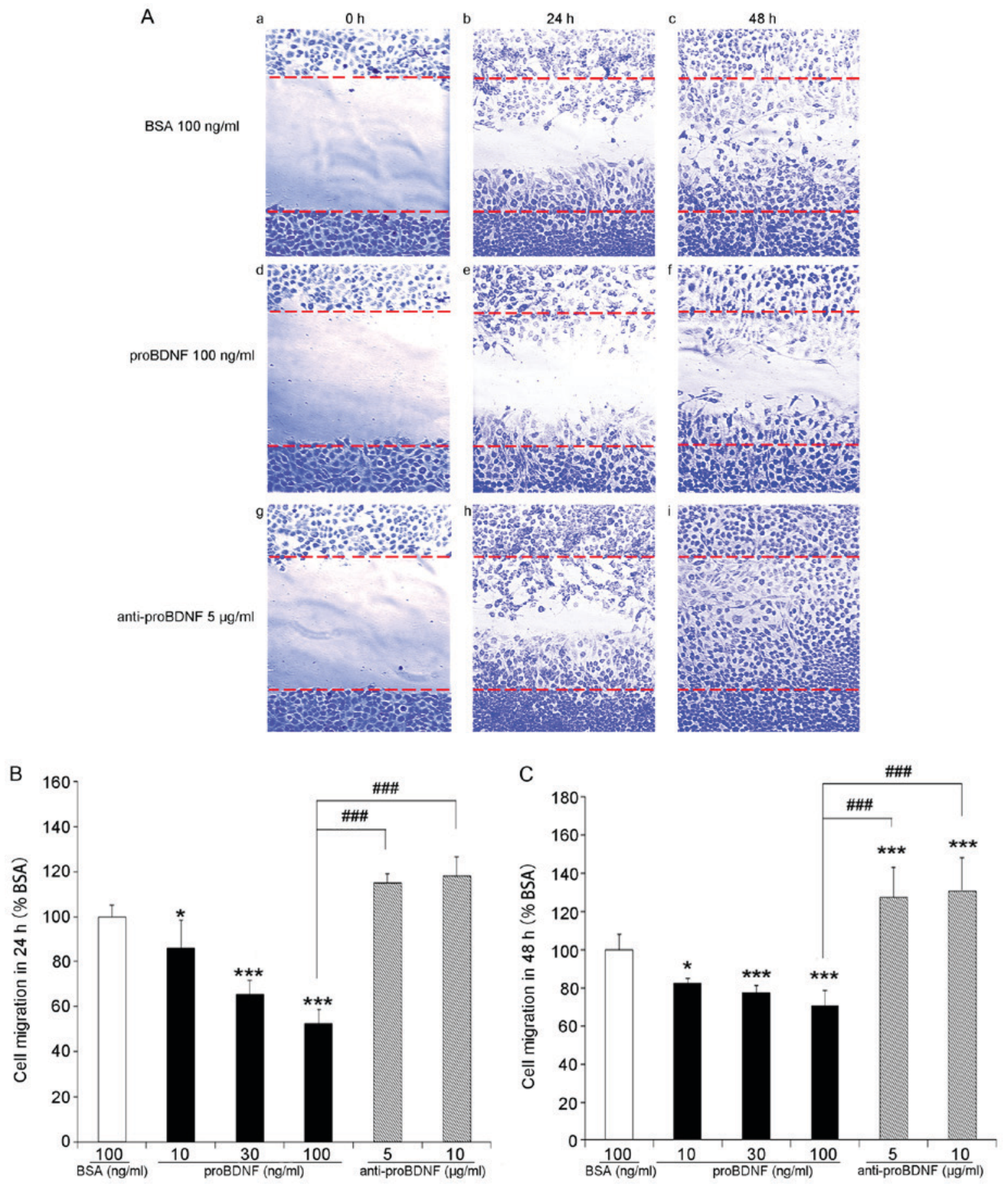

Figure 4. Scratch assay of OLN-93 cells in vitro. (A) Photomicrographs of cell migration to the scratch zone at different time points (magnification, x20). (a-c) control group without any treatment at $0,24,48 \mathrm{~h}$. (d-f) proBDNF treatment group with $100 \mathrm{ng} / \mathrm{ml}$ proBDNF at $0,24,48 \mathrm{~h}$. (g-i) proBDNF antibody treatment group with $5 \mu \mathrm{g} / \mathrm{ml}$ proBDNF antibody at $0,24,48 \mathrm{~h}$. (B and C) Quantitative assessment of cells migrated into scratched zone. For each condition, three representative fields within the scratch were photographed. Data are presented as a percentage of cells migration into scratch zone in culture medium group (control, 100\%) AVONA F=298.336 (B); F=280.230 (C). "P<0.05, ${ }^{* * * *} \mathrm{P}<0.001$ vs. BSA (100\%); ${ }^{\# \# "} \mathrm{P}<0.001$ as indicated. BSA, bovine serum albumin; BDNF, brain-derived neurotrophic factor; ANOVA, one-way analysis of variance.

was conducted to check the proliferative activities after $24 \mathrm{~h}$ of incubation. Under both the treatments, the percentage of proliferating cells significantly increased in comparison with those in the normal sheep IgG control group (Fig. 3C) ( $\mathrm{P}=0.00206$ in $\mathrm{p} 75 \mathrm{NTRECD}-\mathrm{fc} ; \mathrm{P}=0.0151$ in anti-p75NTR).

Moreover, we treated OLN-93 cells with proBDNF and p75NTR antibody. The cells were co-incubated with $100 \mathrm{ng} / \mathrm{ml}$ of proBDNF and $10 \mu \mathrm{g} / \mathrm{ml}$ of p75NTR antibody for $24 \mathrm{~h}$. Treated cells had better proliferative activities than those in the proBDNF group (Fig. 3C) $(\mathrm{P}=0.000103)$ but had no significant differences in comparison with those in the BSA group (Fig. 3C) $(\mathrm{P}=0.264)$. This indicated that proBDNF can inhibit OLN-93 cell proliferation via the p75NTR pathway and that proBDNF can be blocked by disruption of p75NTR signal transduction with the soluble receptor body or antibody.

proBDNF inhibits OLN-93 cell migration. Both proliferation and migration are critical steps in the regeneration and repair 


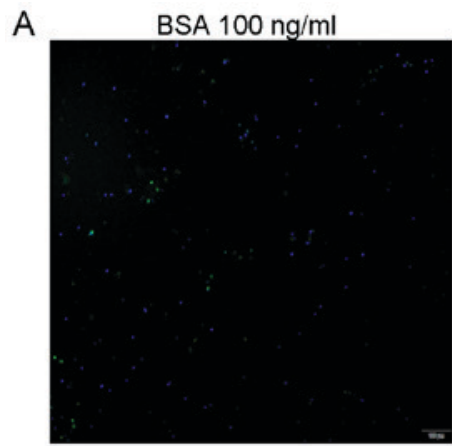

proBDNF $100 \mathrm{ng} / \mathrm{ml}$

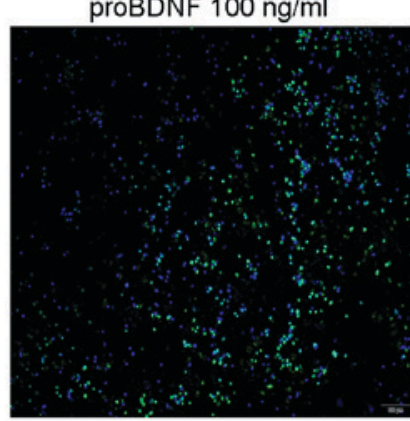

B

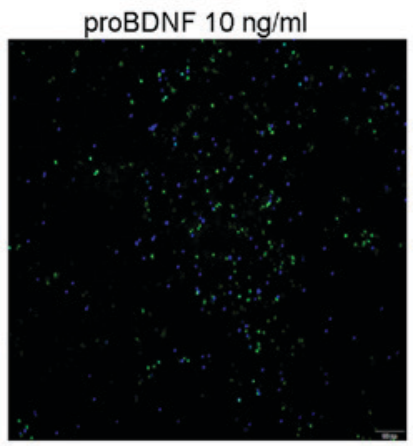

anti-proBDNF $10 \mu \mathrm{g} / \mathrm{ml}$

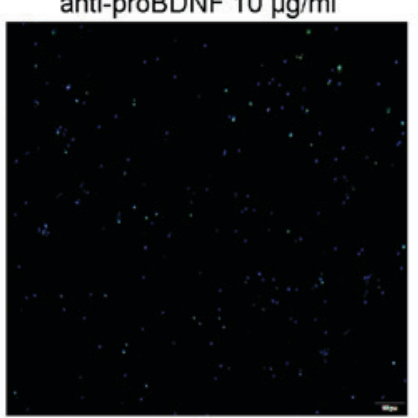

\#

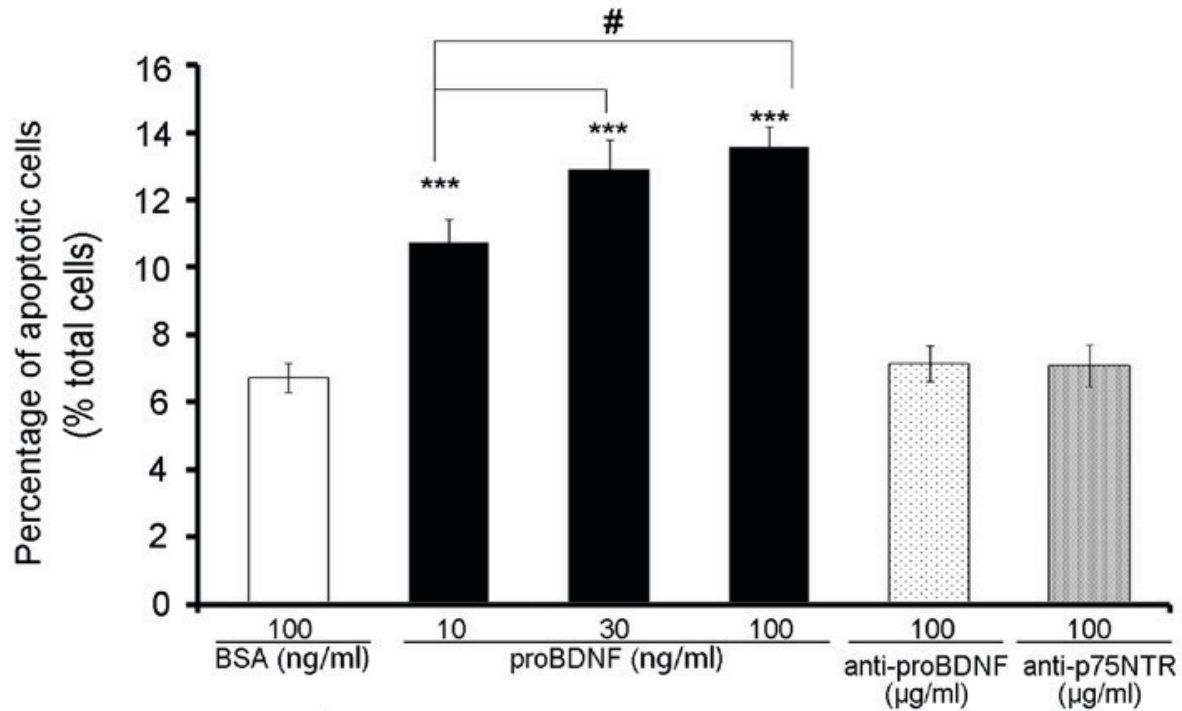

Figure 5. OLN-93 cell apoptosis was assessed using activated caspase 3 immunostaining. (A) Apoptotic cells were stained by activated caspase 3 (green) in cultured OLN-93 cells with proBDNF treatment and BSA control. DAPI (blue) was used to label and quantify total cell number (magnification, x10). (B) Percentage of apoptotic cells after $24 \mathrm{~h}$ with gradient concentrations of proBDNF (10, 30, $100 \mathrm{ng} / \mathrm{ml}) .100 \mathrm{ng} / \mathrm{ml} \mathrm{BSA}, 100 \mu \mathrm{g} / \mathrm{ml} \mathrm{anti}-\mathrm{proBDNF}$ and $100 \mu \mathrm{g} / \mathrm{ml}$ anti-p75NTR were treated as the control. The apoptotic percentage was calculated as the $\%$ of total cell numbers in each slice. ANOVA F=22.967. ${ }^{* * * *} \mathrm{P}<0.001$ vs. BSA group. ${ }^{\#} \mathrm{P}<0.1$ compared with $10 \mathrm{ng} / \mathrm{ml}$ proBDNF treatment group. BSA, bovine serum albumin; BDNF, brain-derived neurotrophic factor; ANOVA, one-way analysis of variance.

after CNS injury. To investigate the function of proBDNF in OLN-93 cell migration, the scratch assay was used. After scratching, a cell-free wound region was generated in 6-well culture plates (Fig. 4Aa, d, g). Serial concentrations of proBDNF (10, 30, and $100 \mathrm{ng} / \mathrm{ml})$ and proBDNF antibody (5 and $10 \mu \mathrm{g} / \mathrm{ml}$ ) were used to treat the cells. After cell growth for 24 and $48 \mathrm{~h}$, a number of cells were observed migrating from the edges into the cell-free scratch region (Fig. 4A). Cells treated with proBDNF showed lower migration activity. A higher concentration of proBDNF resulted in the migration of fewer cells, indicating a dose-dependent inhibition of cell migration by proBDNF (Fig. 4B and C) $(\mathrm{P}=0.0112$ in $10 \mathrm{ng} / \mathrm{ml} ; \mathrm{P}=0.000104$ in $30 \mathrm{ng} / \mathrm{ml} ; \mathrm{P}=0.000229$ in $100 \mathrm{ng} / \mathrm{ml})$.

In comparison with the proBDNF group, more cells migrated into the scratch wound region in the proBDNF antibody (5 or $10 \mu \mathrm{g} / \mathrm{ml}$ ) treatment group; however, the population of migrated cells between different anti-proBDNF concentrations showed no statistical differences (Fig. 4B and C) $(\mathrm{P}=0.24$ in $24 \mathrm{~h}$; $\mathrm{P}=0.50$ in $48 \mathrm{~h}$ ).

proBDNF induces $O L N-93$ cell apoptosis. As a member of the cysteine-aspartic acid protease family, caspase-3 is activated when cell apoptosis occurs (13). In this study, we applied the 
activated caspase-3 antibody to observe apoptosis of OLN-93 cells that were treated with proBDNF $(10,30,100 \mathrm{ng} / \mathrm{ml})$ and BSA (100 ng/ml) (Fig. 5A).

As expected, the percentage of apoptotic cells in the proBDNF group was significantly higher than that in the BSA group (Fig. 5B) $(\mathrm{P}=0.0000384)$. Moreover, with an increase in the dose of proBDNF, more cells were found to be caspase-3-positive (Fig. 5B) $(\mathrm{P}=0.024)$.

\section{Discussion}

Mature BDNF promotes neural differentiation and survival (14) and also plays an important role in proliferation, migration and myelination of oligodendrocytes (15). However, the BDNF precursor, proBDNF, is involved in inhibitory activities in the CNS such as promoting neuron apoptosis, inhibiting neurite outgrowth and cell proliferation and survival via p75NTR and co-receptor sortilin (16-19). The effects of proBDNF on oligodendrocyte have remained unclear. According to our studies, the inhibitory effect of proBDNF on OLN-93 cells is dose-dependent and can be blocked by the proBDNF antibody (Fig. 2). These results indicated the involvement of exogenous and endogenous proBDNF in the viability of oligodendrocyte-like cells.

Endogenous and exogenous proBDNF suppressed OLN-93 proliferation and migration. In our previous studies, we observed that proBDNF inhibited the migration of $\mathrm{ED}^{+}$macrophages after SCI (7) and of granule cells in the developing cerebella (20). This result suggests that similar to neurons, proBDNF may exert negative effects on the migration of non-neuronal cells. In order to investigate this, the scratch assay was performed. Under a standardized wound condition and same incubation period, the migration was inhibited by proBDNF in a dose-dependent manner. Higher concentrations of proBDNF had higher inhibitory activities on cell migration, while treatment with proBDNF antibody facilitated the migration (Fig. 4). Further, OLN-93 proliferation, as investigated by BrdU staining, showed similar results (Fig. 3). These results indicate that proBDNF may be a mitosis suppressor, which prevents the proliferation and migration of oligodendrocyte precursor cell (OPC)s after SCI, and that its detrimental effects can be inhibited by proBDNF antibodies.

Both $\mathrm{mBDNF}$ and proBDNF mediate their biological activities by binding to the cell surface receptors. It is a common phenomenon that the receptors which combine with mNTs always may combine with proNTs; even though to mediate a different signal. The four main related receptors are tyrosine kinase receptor (Trk) (21), p75NTR (22) tumor necrosis factor (TNF) (23) and sortilin (24). Because of the difference in 3D structure, proNTs cannot combine with the Trk receptor (25), however, it has a higher affinity to p75NTR and sortilin (26).

P75NTR, as a receptor, can be combined with all members of the NTs family. When combined with mNTs, P75NTR shows protective effects on cells, which can promote neuronal survival, myelination and migration. When combined with pro-NTs, P75NTR mainly mediates the apoptosis of cell. It is significant that although the Trk receptor binds to mNTs can mediate cell survival (27), when p75NTR and Trk are both on the cell surface, p75NTR plays a dominant role in apoptosis. This may be due to the stronger affinity of p75NTR to the pro-NTs. It can form a high affinity receptor complex and conduct the apoptosis signal. In this process, sortilin has played a key synergy.

Sortilin is a transmembrane protein that belongs to the Vps10p fragment receptor family (28). It has a high affinity for proBDNF and p75NTR. In fact, sortilin exists in the way of the co-receptor in the reaction between pro-NTs and p75NTR (29). Sortilin can form a stable sortilin/p75NTR complex with p75NTR. In the effect of pro-NTs, the affinity of the compound is 10 times higher than that of mNTs, indicating that the sortilin/p75NTR complex is more inclined to combine with proBDNF rather than mBDNF. Further studies also found that pro-NTs binding to sortilin/p75NTR showed stronger stability to proteolysis and denaturation, and more difficult to decompose and destroy (24). Therefore, sortilin can protect pro-NTs from decomposition and destroy, thus prolonging the time of action of pro-NTs and intensifying the apoptosis process of cells.

In the present study, we found that exogenous proBDNF promotes cell apoptosis in a dose-dependent manner (Fig. 5), indicating that proBDNF induces OLN-93 cell apoptosis. In order to investigate the presence of the p75NTR signal transduction pathway in OLN-93 cells, p75NTR functional antibody and recombinant fusion molecule of p75NTRECD-fc were used to inhibit the functions of p75NTR (Fig. 3D). As expected, the obtained results showed specific suppression of proBDNF when p75NTR was blocked, suggesting that the functions of proBDNF are mediated via the p75NTR signal transduction pathway. Considering the important role of oligodendrocytes in vivo, these data suggest that the proBDNF/p75NTR pathway is essential for the functions of oligodendrocytes after CNS injury.

Mature oligodendrocytes are located in the outer rim of the grey matter in the spinal cord (30). After CNS injury and cell loss, cell migration of proliferative OPCs can be observed (31). Our previous studies have shown that proBDNF inhibits the migration of cerebellar granule cells during development (18) in addition to inhibiting macrophage infiltration in the injured spinal cord (7). In this study, the scratch assay performed using OLN-93 cells showed that proBDNF inhibits cell migration in vitro (Fig. 5).

In summary, we demonstrated that exogenous and endogenous proBDNF negatively regulates the proliferation and migration of OPC-like cells in vitro. Antibodies raised against the BDNF pro-domain or p75NTR pathway blocker p75NTRECD-fc effectively suppressed the functions of proBDNF and facilitated cell proliferation and migration as well as reduced the apoptosis of OPC-like cells, indicating their therapeutic value for functional recoveries after SCI. However, additional in vivo studies are needed; our research group has been actively conducting further investigations in this field.

\section{Acknowledgements}

The authors would like to thank Dr Moses Chao from New York University School of Medicine, (New York, NY, USA) for providing the mouse antibody to p75NTR (9650). 


\section{Funding}

The present study was supported by Australian National Health and Medical Research Council (grant nos. 375109 and 595937) to XFZ., the National Natural Science Foundation of China (grant no. 81070982) and Tianjin Natural Science Foundation (grant no. 10JCZDJCI18800) to SQF

\section{Availability of data and materials}

All data generated or analyzed during this study are included in this published article.

\section{Authors' contributions}

XFZ and SF conceived the study. SL conducted the analyses. WG, HZ, JHZ and LT also analysed the data. All authors contributed to the writing and revisions of the manuscript.

\section{Ethics approval and consent to participate}

Not applicable.

\section{Consent for publication}

Not applicable.

\section{Competing interests}

The authors declare that they have no competing interests.

\section{References}

1. Zhou XF, Song XY, Zhong JH, Barati S, Zhou FH and Johnson SM: Distribution and localization of pro-brain-derived neurotrophic factor-like immunoreactivity in the peripheral and central nervous system of the adult rat. J Neurochem 91: 704-715, 2004.

2. Provenzano MJ, Minner SA, Zander K, Clark JJ, Kane CJ, Green SH and Hansen MR: p75(NTR) expression and nuclear localization of p75(NTR) intracellular domain in spiral ganglion Schwann cells following deafness correlate with cell proliferation. Mol Cell Neurosci 47: 306-315, 2011.

3. Banik NL, Powers JM and Hogan EL: The effects of spinal cord trauma on myelin. J Neuropathol Exp Neuro 39: 232-244, 1980.

4. Song XY, Li F, Zhang FH, Zhong JH and Zhou XF: Peripherally-derived BDNF promotes regeneration of ascending sensory neurons after spinal cord injury. PLoS One 3: e1707, 2008

5. Lee R, Kermani P, Teng KK and Hempstead BL: Regulation of cell survival by secreted proneurotrophins. Science 294 1945-1948, 2001.

6. Beattie MS, Harrington AW, Lee R, Kim JY, Boyce SL, Longo FM, Bresnahan JC, Hempstead BL and Yoon SO: ProNGF induces p75-mediated death of oligodendrocytes following spinal cord injury. J Neuron 36: 375-386, 2002.

7. Wong I, Liao H, Bai X, Zaknic A, Zhong J, Guan Y, Li HY, Wang YJ and Zhou XF: ProBDNF inhibits infiltration of ED1+ macrophages after spinal cord injury. Brain Behav Immun 24: 585-597, 2010

8. Richter-Landsberg C and Heinrich M: OLN-93: A new permanent oligodendroglia cell line derived from primary rat brain glial cultures. J Neurosci Res 45: 161-173, 1996.

9. Fan YJ, Wu LL, Li HY, Wang YJ and Zhou XF: Differential effects of pro-BDNF on sensory neurons after sciatic nerve transection in neonatal rats. Eur J Neurosci 27: 2380-2390, 2008

10. Liang CC, Park AY and Guan JL: In vitro scratch assay: a convenient and inexpensive method for analysis of cell migration in vitro. Nat Protoc 2: 329-333, 2007
11. Trotter J, Karram K and Nishiyama A: NG2 cells: Properties, progeny and origin. Brain Res Rev 63: 72-82,2010.

12. Wang YJ, Wang X, Lu JJ, Li QX, Gao CY, Liu XH, Sun Y, Yang M, Lim Y, Evin G, et al: p75NTR regulates Abeta deposition by increasing Abeta production but inhibiting Abeta aggregation with its extracellular domain. J Neurosci 31: 2292-2304, 2011.

13. Salvesen GS: Caspases: Opening the boxes and interpreting the arrows. Cell Death Differ 9: 3-5, 2002.

14. Henderson CE, Camu W, Mettling C, Gouin A, Poulsen K, Karihaloo M, Rullamas J, Evans T, McMahon SB, Armanini MP, et al: Neurotrophins promote motor neuron survival and are present in embryonic limb bud. Nature 363: 266-270, 1993.

15. VonDran MW, Singh H, Honeywell JZ and Dreyfus CF: Levels of BDNF impact oligodendrocyte lineage cells following a cuprizone lesion. J Neurosci 31: 14182-14190, 2011.

16. Arnett MG, Ryals JM and Wright DE: Pro-NGF, sortilin, and p75NTR: Potential mediators of injury-induced apoptosis in the mouse dorsal root ganglion. Brain Res 1183: 32-42, 2007.

17. Chen LW, Yung KK, Chan YS, Shum DK and Bolam JP: The proNGF-p75NTR-sortilin signalling complex as new target for the therapeutic treatment of Parkinson's disease. CNS Neurol Disord Drug Targets 7: 512-523, 2008.

18. Xu ZQ, Li J, Deng J, Jiang XJ and Zhou HD: Effects of proBDNF on cell proliferation and differentiation in hippocampal dentate gyrus in Alzheimer' disease rat model. Zhonghua Yi Xue Za Zhi 90: 1353-1356, 2010 (In Chinese).

19. Sun Y, Lim Y, Li F, Liu S, Lu JJ, Haberberger R, Zhong JH and Zhou XF: ProBDNF collapses neurite outgrowth of primary neurons by activating RhoA. PLoS One 7: e35883, 2012.

20. Xu ZQ, Sun Y, Li HY, Lim Y, Zhong JH and Zhou XF: Endogenous proBDNF is a negative regulator of migration of cerebellar granule cells in neonatal mice. Eur J Neurosci 33: 1376-1384, 2011

21. Huang EJ and Reichardt LF: Trk receptors: Roles in neuronal signal transduction. Annu Rev Biochem 72: 609-642, 2003.

22. Yoon SO, Casaccia-Bonnefil $\mathrm{P}$, Carter $\mathrm{B}$ and Chao MV: Competitive signaling between TrkA and 75 nerve growth factor receptors determines cell survival. J Neurosci 18: 3273-3281, 1998.

23. Johansson $M$, Jönsson $M$, Norrgård $O$ and Forsgren S: New aspects concerning ulcerative colitis and colonic carcinoma: Analysis of levels of neuropeptides, neurotrophins, and TNFalpha/TNF receptor in plasma and mucosa in parallel with histological evaluation of the intestine. Inflamm Bowel Dis 14: 1331-1340, 2008

24. Teng HK, Teng KK, Lee R, Wright S, Tevar S, Almeida RD, Kermani P, Torkin R, Chen ZY, Lee FS, et al: ProBDNF induces neuronal apoptosis via activation of a receptor complex of p75NTR and sortilin. J Neurosci 25: 5455-5463, 2005.

25. Xu GY, Hughes MG, Ye Z, Hulsebosch CE and McAdoo DJ: Concentrations of glutamate released following spinal cord injury kill oligodendrocytes in the spinal cord. Exp Neurol 187: 329-336, 2004

26. Feng D, Kim T, Ozkan E, Light M, Torkin R, Teng KK, Hempstead BL and Garcia KC: Molecular and structural insight into proNGF engagement of p75NTR and sortilin. J Mol Biol 396: 967-984, 2010.

27. Zhang Y, Moheban DB, Conway BR, Bhattacharyya A and Segal RA: Cell surface Trk receptors mediate NGF-induced survival while internalized receptors regulate NGF-induced differentiation. J Neurosci 20: 5671-5678, 2000.

28. Nykjaer A, Lee R, Teng KK, Jansen P, Madsen P, Nielsen MS, Jacobsen C, Kliemannel M, Schwarz E, Willnow TE, et al: Sortilin is essential for proNGF-induced neuronal cell death. Nature 427: 843-848, 2004

29. Volosin M, Song W, Almeida RD, Kaplan DR, Hempstead BL and Friedman WJ: Interaction of survival and death signaling in basal forebrain neurons: Roles of neurotrophins and proneurotrophins. J Neurosci 26: 7756-7766, 2006.

30. Horner PJ, Power AE, Kempermann G, Kuhn HG, Palmer TD, Winkler J, Thal LJ and Gage FH: Proliferation and differentiation of progenitor cells throughout the intact adult rat spinal cord. J Neurosci 20: 2218-2228, 2000.

31. McTigue DM, Horner PJ, Stokes BT and Gage FH: Neurotrophin-3 and brain-derived neurotrophic factor induce oligodendrocyte proliferation and myelination of regenerating axons in the contused adult rat spinal cord. J Neurosci 18: 5354-5365, 1998. 